\title{
Os desafios de implantar um curso de Psicologia na Bahia na mudança do século
}

\section{The challenges of implementing a Psychology course in Bahia in the turn of the century}

\section{Maria Rosalia de Azevedo Correia}

UniFTC, UniRuy Wyden (Salvador). Bahia, Brasil. ma_rosalia@yahoo.com.br

\begin{abstract}
RESUMO | O texto objetiva registrar o período de implantação de um curso de Psicologia em uma instituição de ensino superior em Salvador Bahia. Trata-se de um relato de experiência sobre a fase de implantação até a consolidação do Curso de graduação em Psicologia da Escola Bahiana de Medicina e Saúde Pública, no ano de 2000, a partir de dados de estudos realizados em uma tese de doutorado e da memória afetiva da autora. Os resultados incluem a produção de um percurso histórico que contextualiza os avanços referentes a história da psicologia no Brasil e as concepções de Psicologia como ciência e profissão no país e na Bahia na virada do século XX para o século XXI. Também foram salientadas as peculiaridades da Bahiana como instituição de ensino voltada para área da saúde e da formação da autora enquanto psicóloga e educadora. Revela uma experiência bem sucedida cujo curso completa 20 anos.
\end{abstract}

PALAVRAS-CHAVE: Formação. Psicologia. Memória. História.

\begin{abstract}
The text aims to record the period of implementation of a psychology course in Salvador Bahia. This is an experience report on the implementation phase of the Graduation Course of Psychology at the Bahiana School of Medicine and Public Health, in 2000, based on data from studies carried out on a doctoral thesis and the affective memory of the author. The results include the production of a historical journey that contextualizes the advances regarding the history of Psychology in Brazil and the conceptions of Psychology as a science and profession in the country and Bahia from the turn of the 20th century to the 21 st century. It was also highlighted the peculiarities of Bahiana as an educational institution focused on the area of health and the formation of the author as a psychologist and educator. It reveals a successful experience whose course completes 20 years.
\end{abstract}

KEYWORDS: Formation. Psychology. Memory. History. 
Foi com muita alegria que recebi o convite para registrar, do meu ponto de vista, o desafio para a implantação do Curso de Psicologia da Escola Bahiana de Medicina e Saúde Pública, no ano de 2000, na cidade de Salvador, Bahia. E sinto-me muito grata pela oportunidade de, 20 anos depois, buscar na memória as condições daquela época e recordar de momentos vividos com muita intensidade, próprios da magnitude desta tarefa como coordenadora do curso. Situações graves, difíceis em alguns momentos, mas tantas outras leves, alegres, sempre desafiadoras, superadas por um forte apoio institucional oferecido pelo prof. Dr. Humberto de Castro Lima, Coordenador Geral da FBDC, e pela presença frequente nas decisões do curso do prof. Gaspare Saraceno, coordenador da Graduação e, acima de tudo, por um grupo de professores parceiros, coesos, competentes e coconstrutores do curso.

$\mathrm{Na}$ verdade, neste texto, pretendo refletir sobre alguns aspectos específicos da implantação do Curso, quais sejam, o momento histórico em que vivia a Psicologia no Brasil e na Bahia na mudança do século, a Bahiana enquanto instituição de ensino, a minha formação como psicóloga e os desafios inerentes a cada uma dessas questões.

A passagem do séc. XX para o séc. XXI foi experienciada pela Psicologia brasileira como um momento particularmente intenso e efervescente. Vivia a categoria um acalorado debate sobre qual a Psicologia que se estava fazendo, qual a que se queria ser e fazer, e quem eram os profissionais que se queria formar.

Recorrendo à história da Psicologia no Brasil, podemos constatar que esta, enquanto fazer profissional, já vinha sendo exercida no Brasil desde o séc. XIX, mediante o desempenho de médicos, educadores e juristas, tendo em vista que o seu saber é oriundo das perguntas da filosofia e faz parte dos questionamentos da própria existência humana. Ela se formaliza enquanto saber acadêmico, quando da criação das Faculdades de Medicina na Bahia e no Rio de Janeiro, nos idos de 1833, e pela introdução das disciplinas psicológicas nos Cursos Normais, por conta da Reforma Benjamim Constant em 1890'. Mas, enquanto profissão e formação acadêmica, foi formalizada no Brasil, em 1962, pela Lei 4119/62, sancionada em 27 de agosto e publicada no D.O da União em 05 de setembro do mesmo ano; foi regulamentada pelo decreto 53.464/64, que além de instituir a Psicologia como profissão, também criou o currículo mínimo para implantação dos cursos e estabeleceu a sua duração em 5 anos².

A implantação dos Cursos de Psicologia no Brasil, portanto, se deu na vigência do período da ditadura militar, que cerceava livres iniciativas, diversidade de pensamento e expressão. Neste mesmo período, a Lei 5540/68, de Diretrizes e Bases da Educação foi proposta, instituindo a Reforma Universitária que, coerente com o pensamento vigente, propunha um currículo fragmentado, sem interlocução com outros saberes e áreas afins, numa perspectiva individualizante, com o objetivo de formar profissionais para uma prática técnica e sociopoliticamente neutra.

Este período histórico que vivia a sociedade brasileira não favoreceu que a Psicologia se diversificasse, se recriasse diante de suas potencialidades, sendo-lhe reservado prioritariamente o lugar de "ajustamento" de pessoas com dificuldades de convivência social, escolar e/ou familiar, criando uma representação social de que psicólogos lidam com pessoas com problemas, inadaptadas ao convívio, com patologias psíquicas severas. Há um foco predominante no modelo clínico de atuação profissional.

Porém, em 1979, o psicólogo Silvio Botomé publicou o texto "A quem nós, psicólogos, servimos de fato?" que veio a se constituir num texto inspirador, que mobilizou toda a categoria para se pensar e pensar a psicologia. Muitas publicações se seguiram, especialmente em 1984 e 1985, veiculadas na Revista "Psicologia Ciência e Profissão", do Conselho Federal de Psicologia, que discutia os desafios para a formação de psicólogos.

\footnotetext{
1 Dados coletados na tese de Doutoramento intitulada "Construção de Identidades em Psicologia", defendida em 2007, no Programa de Pesquisa e Pósgraduação em Educação da Faculdade de Educação da Universidade Federal da Bahia, de minha autoria.

${ }^{2}$ Idem.

${ }^{3}$ Botomé, S. P. (1979). A quem, nós, psicólogos, servimos de fato? Psicologia. 5(1), 1-15
} 
E outros fatos marcantes se seguiram, como a publicação pelo Conselho Federal de Psicologia, em 1988, da primeira grande pesquisa, intitulada "Quem é o psicólogo brasileiro", que serviu como uma radiografia da Psicologia que se praticava no Brasil na época e constatou a predominância da atividade clínica, seguida da atuação em escolas e em organizações, que vão se configurar como as três grandes áreas tradicionais da atuação do psicólogo.

Mas os ventos de uma democracia iniciante autorizavam a convocar, discutir e propor novos caminhos para a Psicologia. Foi assim que, em 1992, o sistema Conselhos (Federal e Regionais) convocou uma reunirão de Coordenadores de Curso de Psicologia de todo o País para discutir, durante 3 (três) dias, os rumos da Psicologia brasileira. E o produto desta reunião é conhecida como a "Carta de Serra Negra", que, com 7 (sete) princípios, propôs diretrizes para o funcionamento dos cursos, no tocante a currículo e estágios, a fim de encaminhar para reformas curriculares. Havia o propósito de um balizamento, para que modificações fossem realizadas nos Cursos, a fim de se formar profissionais mais críticos, mais bem preparados e sintonizados com as demandas sociais da época. Assim, novas discussões se seguiram em outros encontros.

Em 1996, foi aprovada, no âmbito do MEC, a Lei da Educação 9394/96, que propõe modificações no funcionamento do ensino superior e apresenta como novidade as Diretrizes Curriculares Nacionais para todos os Cursos superiores e, para cada área, foi convocada uma comissão de especialistas para redigir essas Diretrizes. A ideia básica é romper com a lógica fragmentada e sequenciada do Currículo Mínimo, apontando para uma orientação sobre princípios, fundamentos, condições de oferecimento e procedimentos para planejamento, implementação e avaliação do curso. Não nomeia matérias ou disciplinas, mas delimita conhecimentos, habilidades e competências a serem adquiridos e desenvolvidos, agrupados em torno de eixos estruturantes. Em 1997, foi constituída a comissão de especialistas psicólogos, patrocinada pelo MEC, que apresentou a primeira versão no início de 1999 e a segunda versão em dezembro deste mesmo ano. Versões estas que não foram aceitas pelo coletivo da Psicologia e, na sequência, seguiram-se muitos embates até a redação final deste documento, que foi preparado pelo Fórum de entidades da Psicologia e foi publicada no D. O da União em 18 de maio de 2004.

Estava posto o nosso grande desafio, qual seja, implantar um curso cuja proposta, elaborada em 1997 e aprovada pelo MEC em 1998, seguisse as proposições do Currículo Mínimo, com sua lógica fragmentada, e era preciso reconhecê-lo mediante parecer de uma Comissão Avaliadora do MEC, afinado com as Diretrizes Curriculares Nacionais ainda não aprovadas. Some-se a isso o fato de o curso estar sediado em uma instituição de ensino com tradição em cursos da área da saúde, numa cidade que, durante 30 anos, teve apenas uma matriz de formação de psicólogos, o Curso de Psicologia da Universidade Federal da Bahia.

Nos idos de 1999/2000, a Escola Bahiana de Medicina e Saúde Pública era uma tradicional e respeitada instituição de ensino baiano que, desde 1952, formava médicos e se definia como vocacionada para a área da saúde, tal como eram os cursos que oferecia. Implantar um Curso de Psicologia, profissão considerada da área da saúde, pela Resolução 218/97 do Conselho Nacional de Saúde, representava para esta instituição não apenas abrir mais um curso, mas introduzir uma visão mais humanizada dos alunos e dos cursos que oferecia, com o reconhecimento da dimensão subjetiva dos sujeitos. Importante citar que, no mesmo momento em que se iniciavam as atividades do Curso de Psicologia, a Bahiana criou o NAPP, o Núcleo de Atenção Psicopedagógica, para dar suporte pedagógico e emocional às demandas dos alunos de todos os cursos.

${ }^{4}$ Serra Negra se refere à cidade gaúcha onde se realizou a reunião. 
Ao implantar o Curso, a proposta da instituição era fazer um Curso diferenciado da matriz única que havia na Bahia e buscar compreender o cenário nacional, para implantar um curso sintonizado com todos os avanços preconizados pelas novas discussões da Psicologia brasileira, que já se desenvolviam com muita força. E a ideia principal era reconhecer a multiplicidade da Psicologia em sua diversidade teórico-metodológica e ampliar as possibilidades de áreas de atuação.

E, nessa perspectiva, tive a oportunidade de conhecer o funcionamento de Cursos em São Paulo e comecei a frequentar todos os fóruns da Psicologia brasileira onde se discutia a formação de psicólogos. Foi assim, em 1999, quando da participação na XXXIX Reunião Anual da Psicologia, patrocinada pela Sociedade Brasileira de Psicologia em Campinas, São Paulo, onde foram apresentadas ao coletivo presente, pela primeira vez, algumas propostas de Diretrizes Curriculares já elaboradas por alguns cursos. Comecei a ouvir as ideias e as práticas de uma Psicologia para além de seus limites tradicionais, o que me encantava.

Em 2000, aconteceu, em São Paulo, a $1^{\text {a }}$ Mostra Nacional de Práticas em Psicologia: Psicologia e Compromisso Social, que marcava uma posição da Psicologia, comprometida com as transformações sociais e, por se tratar de um evento em que psicólogos de todo o Brasil apresentavam suas intervenções em variados campos de atuação, com aportes teóricos e metodológicos diversos e clientela diversificada, foi possível ampliar o leque das possibilidades que a Psicologia pode proporcionar enquanto ciência e fazer profissional.

É importante demarcar que, enquanto vivíamos sob a égide de um sistema autoritário, reações foram se consolidando pelo Brasil e mostrando possibilidades de fazer psicologia com uma outra lógica que não a acadêmica, a tradicional. Este é o lócus onde foi gestada e se desenvolveu uma psicologia social comunitária, que trabalhava com sujeitos coletivos oriundos dos diversos estratos socioeconômicos, com metodologias próprias, de preferência grupais, e que apontava para novas configurações de uma Psicologia brasileira.
Essa diversidade aparecia frequentemente e era valorizada em todos os encontros de coordenadores de cursos de Psicologia que frequentei ao longo dos períodos de implantação do curso, como o III Encontro Nacional da ABEP em 2001; o I Congresso Brasileiro Ciência e Profissão, em São Paulo, em 2002; o IV Encontro Nacional da ABEP, em João Pessoa, em 2003 e o I Seminário Nacional sobre as Diretrizes Curriculares para os Cursos de Psicologia, em Brasília, 2004.

Nesse particular, é importante demarcar a minha formação em Psicologia na área clínica, em uma matriz fenomenológica existencial, inicialmente com uma formação rogeriana ${ }^{5}$ e posteriormente no sociopsicodrama ${ }^{6}$, que encontrava eco nas proposições inovadoras debatidas a cada encontro com os demais coordenadores de curso e que fugiam das duas polaridades - psicanálise e behaviorismo. Além do mais, tinha uma prática profissional na área da educação, aderindo às proposições críticas e dialógicas de Paulo Freire e de uma Pedagogia Histórico-Crítica. Também havia concluído um mestrado no Programa de Pósgraduação em Educação pela Universidade Federal da Bahia, fazendo uma tessitura teórica que articulava conhecimentos do Projeto Socionômico de Jacob Levi Moreno, com a Psicologia Social e a Pedagogia Histórico-Crítica.

Todos esses aspectos constituíram o lastro onde foi tecida e elaborada uma proposta para o recém-criado Curso de Psicologia da Bahiana. Muitas "coisas" precisaram ser feitas para minimizar o impacto desta grande transformação em um momento crucial de um curso que estava se iniciando. A primeira delas foi montar uma comissão de professores que pudessem pensar, de uma forma aprofundada, as possibilidades exequíveis, mantendo a qualidade e a consistência dos conteúdos do curso. Dessa maneira, a comissão foi formada pelas professoras/psicólogas Sonia Regina Fernandes, Telma Mascarenhas, Cristina Linhares e Lilian Darzé, orientadas por mim, a coordenadora do Curso. Era necessário reordenar o fluxograma de integralização das disciplinas, com revisão de conteúdos curriculares e bibliografias; criar os eixos temáticos propostos pelas Diretrizes; eliminar algumas disciplinas e criar novas; redimensionar cargas horárias; introduzir o trabalho

${ }^{5}$ Abordagem Centrada na Pessoa, desenvolvida por Carl Rogers.
${ }^{6}$ Projeto Socionômico de Jacob Levi Moreno, que inclui o Psicodrama em suas formulações. 
monográfico; criar as ênfases curriculares; reelaborar a proposta de estágio, dividindo-o em estágios básicos e específicos, e criar as atividades complementares. E esta tarefa, pensada e estruturada por esta comissão, foi submetida, periodicamente, ao grupo de professores em inúmeras reuniões, ocasiões em que todos os professores puderam colaborar na construção das ementas, na definição das bibliografias, na sequência teórica de cada cadeia de disciplinas e conteúdos e na definição do que seriam estágios básicos, cuja maior preocupação era não trazer precocemente as áreas de especialização, mas desenvolver competências próprias da escuta psicológica em quaisquer contextos de atuação, tal como proposto nas Diretrizes Curriculares.

A Comissão Verificadora do MEC visitou o curso para o seu reconhecimento em outubro de 2013, dando a nota máxima para o Projeto Político Pedagógico, e, em dezembro de 2014, formou a sua primeira turma de psicólogos, o que para mim se constitui o marco que consolida a sua implantação.

Tenho muito que agradecer. Em primeiro lugar, ao Universo que me proporcionou viver essa fascinante experiência. A todas as pessoas envolvidas nesse projeto, desde os funcionários administrativos, que desempenhavam os seus papéis com muita competência; ao grupo de professores unidos, fortes, sempre dispostos a acertar e a crescer juntos; aos alunos que, ao nos questionarem, nos fizeram crescer e buscar sempre o melhor, e à minha rede afetiva, sempre disposta a ouvir e dar a continência necessária nos momentos difíceis e de celebrar as pequenas e grandes vitórias.

Os dados deste depoimento estão na tese de doutoramento anteriormente citada, e de minha autoria, e as demais informações fui buscar na minha memória afetiva, o que me proporcionou uma enorme alegria, a de estar revivendo/escrevendo sobre um período em que trabalhei muito, mas no qual fui muito feliz.

\section{Conflitos de interesses}

Nenhum conflito financeiro, legal ou político envolvendo terceiros (governo, empresas e fundações privadas, etc.), foi declarado para nenhum aspecto do trabalho submetido (incluindo, mas não se limitando a subvenções e financiamentos, participação em conselho consultivo, desenho de estudo, preparação de manuscrito, análise estatística, etc.).

\section{Referências}

Correia, M. R. A. (2007). Construção de Identidades em Psicologia. [Tese de Doutorado, Universidade Federal da Bahia, Faculdade de Educação]. Repositório UFBA. https:// repositorio.ufba.br/ri/bitstream/ri/10598/1/Maria\%20 Rosalia\%20de\%20Azevedo.pdf

Decreto $n^{\circ}$ 53.464, de 21 de janeiro de 1964. Regulamenta a Lei $n^{\circ}$ 4.119, de agosto de 1962, que dispõe sobre a Profissão de Psicólogo. https://transparencia.cfp.org.br/wp-content/ uploads/2008/08/decreto_1964_534641.pdf

Lei $n^{\circ}$ 4.119, de 27 de agosto de 1962. Dispõe sôbre os cursos de formação em psicologia e regulamenta a profissão de psicólogo. http://www.planalto.gov.br/ccivil_03/leis/19501969/L4119.htm

Lei $n^{\circ} 5.540$, de 28 de novembro de 1968. Fixa normas de organização e funcionamento do ensino superior e sua articulação com a escola média, e dá outras providências. https://www2.camara.leg.br/legin/fed/lei/1960-1969/lei5540-28-novembro-1968-359201-publicacaooriginal-1-pl. html

Lei n. 9.394/96, de 20 de dezembro de 1996. Estabelece as diretrizes e bases para a educação nacional. http://portal.mec.gov. br/seesp/arquivos/pdf/lei9394_ldbn1.pdf 